\title{
A Comparative Analysis of Expression of Selected Genes During Induction of Differentiation in Neonatal Rats by Deprival of FSH or by Hyperthyroidism
}

\author{
Chitra Lekha Dahia, Mary Nirmala Sarkar and A.J. Rao*
}

Department of Biochemistry, Indian, Institute of Science, Bangalore 560012, India

\begin{abstract}
The effect of Follicle Stimulating Hormone (FSH) deprivation, or hyperthyroidism, on the expression of selected genes in Sertoli cells of neonatal rats was compared, and significant differences were revealed. While hyperthyroidism resulted in both arrest of proliferation and expression of differentiation markers, FSH deprivation only resulted in arrest of proliferation, as assessed by a decrease in such proliferation markers as connective tissue growth factor (CTGF) and collagen 12A1 and the expression of differentiation markers, such as androgen binding protein, transferrin and clusterin. In Sertoli cells isolated from hyperthyroid rats, a decrease in the expression of FSH receptor was also observed. Microarray analysis of RNA from FSH-deprived or hyperthyroid neonatal rat Sertoli cells suggests that molecular events associated with arrest of proliferation by hyperthyroidism appear to be different from arrest of proliferation by FSH deprivation.
\end{abstract}

Keywords: FSH, thyroid hormone, proliferation, differentiation, microarray, sertoli cells.

\section{INTRODUCTION}

In rats, Sertoli cells divide rapidly at birth, but their proliferation declines during the neonatal period and ceases by $15-18$ days postnatal $[1,2]$. Our previous studies have shown that Sertoli cell proliferation peaks at day 9 after birth in rats [3]. The fact that the primary stimulus for Sertoli cell proliferation is Follicle Stimulating Hormone (FSH) has been established by both in vitro and in vivo studies [3-10]. After postnatal day 18, Sertoli cell proliferation is arrested despite continued exposure to FSH [11]. Arrest of proliferation of Sertoli cells is accompanied by their differentiation at 14-21 days postnatal, and this is ascertained by increased production of markers characteristic of mature Sertoli cells. These markers are secretory proteins, such as androgen binding protein (ABP) and transferrin, which are important for germ cells, as well as the synthesis of proteins which are involved in the formation of specialized tight junctions between neighboring Sertoli cells to establish the blood-testis-barrier $[12,13]$. The importance of FSH in regulating the proliferation of Sertoli cells during the neonatal period is well established, but the differentiation of Sertoli cells, even in the presence of FSH, suggests the possibility that other factors may be involved in the regulation of the transition of Sertoli cells from a proliferative to a differentiative state during this period.

Thyroid hormone plays a crucial role in Sertoli cell development. Neonatal testes express high levels of thyroid hormone receptors, predominantly in Sertoli cells [9, 14-18]. The expression of thyroid hormone receptors in Sertoli cells

*Address correspondence to this author at the Department of Biochemistry, Indian Institute of Science, Bangalore, India; Tel: 91-080-22932308; 23608660; Fax: 91-080-23608660; E-mail: ajrao_2000@yahoo.com changes with development. High levels of thyroid hormone receptors are expressed during the fetal and neonatal period, and the increase in the expression of thyroid hormone receptors coincides with the arrest of proliferation of Sertoli cells around day 18 [14]. The regulation of Sertoli cells by thyroid hormone can be studied by using hypothyroid [17, 19-21] animal model systems. Studies have shown that transient neonatal and prepubertal hypothyroidism extends throughout the period of proliferation by delaying Sertoli cell maturation, resulting in an increased number of Sertoli cells in the adult testis $[2,22]$. With this in mind, it should be noted that each Sertoli cell supports a fixed number of germ cells [23], suggesting their importance in maintaining testicular functions. The number of Sertoli cells present in the adult testis depends on both the duration of the proliferative phase and the rate of division during that phase. In contrast, transient neonatal hyperthyroidism resulted in an early cessation of Sertoli cell proliferation and had a concomitant stimulatory effect on their maturation, as observed by canalization of seminiferous tubules, decreased testis size and sperm production [20,21, 24, 25]. Our previous studies have shown that deprivation of endogenous FSH by administration of specific antiserum to FSH (FSH $\mathrm{a} / \mathrm{s}$ ) in neonatal rats resulted in decreased proliferation of Sertoli cells with a concomitant decrease in $\operatorname{BrdU}$ incorporation and decrease in proliferation markers such as PCNA and Cyclin A2 [3]. Interestingly, deprivation of FSH only had a marginal effect on differentiation markers, such as ABP and transferrin, during this period [3]. The effects following FSH deprivation and hyperthyroidism are similar insofar as proliferation is concerned; therefore, it was of interest to compare the changes in differentiation markers following these treatments. In the present study, we have compared the effect of FSH deprivation or administration of thyroid hormone on neonatal rat Sertoli cell proliferation 
under in vitro and in vivo conditions. Our results reveal that hyperthyroidism induces premature differentiation of Sertoli cells. To obtain insights into the molecular events underlying the action of thyroid hormone on the growth and differentiation of Sertoli cells, we have carried out a microarray analysis of RNA from euthyroid and hyperthyroid neonatal rat Sertoli cells using a rat oligo array representing 5600 rat genes and compared the profile obtained with hyperthyroid rats and control immature rats with effects following FSH deprivation and adult rat Sertoli cells.

\section{MATERIALS AND METHODS}

\subsection{Animals and Treatment}

Seven-day-old Wistar rats were obtained from the Central Animal Facility, Indian Institute of Science, Bangalore, India, and maintained under standard conditions (12 h of light and $12 \mathrm{~h}$ of dark, with water and pelleted food ad libitum). The animal procedures employed in the study were approved by the Institutional Ethical Committee.

Hyperthyroidism was achieved in neonatal rats by administration of T3 (100 $\mu \mathrm{g} / \mathrm{kg}$ body weight/ day) in saline, subcutaneously, from birth to 13 days postnatal. The dosage was based on the reported study by Auharek et al. [26]. Control or euthyroid rats were administered with equal volume of saline. On day 14, Sertoli cells were isolated and processed for either in vitro incubation studies or isolation of RNA.

Antiserum to highly purified ovine $\mathrm{FSH}$ (oFSH) was used to neutralize the endogenous FSH in neonatal rats. FSH antiserum (FSH a/s) was raised in the adult male bonnet monkey (Maccaca radiata) as previously described [3]. The absence of contaminating antibodies to LH was established by absence of binding to ${ }^{125} \mathrm{I}-\mathrm{hCG}$ and the inability of the antiserum to inhibit LH-stimulated testosterone production by Leydig cells [27]. The ability of antiserum to neutralize endogenous FSH has been established in neonatal male rats [3]. Rats administered normal monkey serum (NMS) served as controls.

In order to study the effect of FSH deprivation on the growth and function of Sertoli cells, seven-day-old neonatal rats were administered $100 \mu \mathrm{l}$ of $\mathrm{FSH}$ a/s or NMS by i.p. route twice a day for 6 days. On the fourteenth day, the animals were sacrificed, and the effect of neutralization of endogenous FSH was assessed.

\subsection{Isolation of Sertoli Cells and Culture}

Sertoli cells were isolated from neonatal (14 days) and adult rats (90 days) as previously described [3, 28]. Briefly, seminiferous tubules were digested in $0.125 \%$ of Trypsin (Sigma Chemical Co., St. Louis, MO, USA) and $10 \mu \mathrm{g} / \mathrm{ml}$ of DNase (Worthington Biochemical Corporation, Lakewood, NJ, USA) in $1 \times$ Hanks Balanced Salt Solution (HBSS) for $20 \mathrm{~min}$. After three washes in $1 \times \mathrm{HBSS}$, the tubules were subjected to two enzymatic digestions with 1 $\mathrm{mg} / \mathrm{ml}$ collagenase (Worthington Biochemical Corporation, Lakewood, NJ, USA) and DNase followed by $1 \mathrm{mg} / \mathrm{ml}$ collagenase, $1 \mathrm{mg} / \mathrm{ml}$ hyaluronidase (Sigma Chemical Co., St. Louis, MO, USA) and DNase for $30 \mathrm{~min}$ each. The cells were washed three times with $1 \times$ HBSS and pelleted down by centrifugation. The cells were resuspended in $1 \mathrm{ml}$ of DMEM Ham-F12 (Sigma Chemical Co., St. Louis, MO, USA) and counted in a hemocytometer. Sertoli cells from neonatal rats were maintained in DMEM Ham-F12 medium containing $10 \mu \mathrm{g} / \mathrm{ml}$ insulin (Sigma Chemical Co., St. Louis, MO, USA) and $5 \mu \mathrm{g} / \mathrm{ml}$ transferrin (Sigma Chemical Co., St. Louis, MO, USA) at $32^{\circ} \mathrm{C}$ in $5 \% \mathrm{CO} 2$. After $24 \mathrm{~h}$ of preculture, Sertoli cells were subjected to hypotonic shock by replacing the medium diluted with water $(1: 10)$ to remove any contaminating germ cells. The characterization of Sertoli cells after hypotonic shock was described earlier [3]. The purity of the Sertoli cells was determined by the absence of germ cells as monitored under the phase contrast microscope. For the absence of Leydig cells, RT-PCR was used to check for LH receptor (LH-R), and for the absence of myoid cells, alkaline phosphatase staining was performed.

\subsection{Cell Proliferation Assay}

The incorporation of BrdU (5-bromodeoxyuridine) in neonatal rat Sertoli cells was used as a measure of proliferative activity. Forty thousand Sertoli cells were cultured per well in quadruplets in a 96-well culture plate. Each group of Sertoli cells was treated with either oFSH (250 ng/ ml) (a kind gift from Prof. Sairam, Clinical Research Institute of Montreal, Canada) or FSH + T3 (250 $\mathrm{ng} / \mathrm{ml}$ oFSH and $100 \mathrm{nM} \mathrm{T3}$ ). The Sertoli cells were cultured in serum-free medium (DMEM Ham-F12) containing $5 \mu \mathrm{g} / \mathrm{ml}$ transferrin (Sigma Chemical Co., St. Louis, MO, USA) and $5 \mu \mathrm{g} / \mathrm{ml}$ insulin (Sigma Chemical Co., St. Louis, MO, USA) for $16 \mathrm{~h}$ at $34^{\circ} \mathrm{C}$ in $5 \% \mathrm{CO}_{2}$. To maintain uniform conditions, cells from neonatal and adult rats were maintained at $34^{\circ} \mathrm{C}$, although Sertoli cells from normal adult rats are generally maintained at $37^{\circ} \mathrm{C}$. The Sertoli cells were then incubated in the presence of $10 \mu \mathrm{M}$ of $\mathrm{BrdU}$ for $4 \mathrm{~h}$. Incorporation of BrdU was assessed using the Amersham $^{\mathrm{TM}}$ Cell Proliferation ELISA Biotrak system according to the manufacturer's protocol (GE Healthcare UK Ltd). The viability/growth of cells following various treatments was verified using the MTT assay as described by Mosmann, [29]. MTT [3-(4,5-dimethylthiazol-2-yl)-2,5biphenyl tetrazolium bromide; Thiazolyl blue] is a watersoluble tetrazolium salt. Dissolved MTT can be converted to an insoluble purple formazan by cleavage of the tetrazolium ring by cellular dehydrogenase enzymes. At the end of the incubation period, $50 \mu \mathrm{l}$ of $5 \mathrm{mg} / \mathrm{ml}$ MTT (i.e., one-tenth of the culture volume) was added to the cultures and further incubated for $3-4$ hours at $37^{\circ} \mathrm{C}$. Following this, the medium was removed and the reaction terminated by the addition of $500 \mu \mathrm{l}$ of acidified isopropanol $(40 \mathrm{mM} \mathrm{HCl}$ in absolute isopropanol) to extract the formazan crystals that had formed. Absorbance of the converted dye was measured at $570 \mathrm{~nm}$ on a UV Max microplate reader (Molecular Devices, Menlo Park, CA). All tests were performed in triplicate, and data are expressed graphically ( $\mathrm{OD}_{570}$ as a function of time).

\subsection{Semi-Quantitative RT-PCR}

Total RNA was extracted from Sertoli cells using TRI reagent (Sigma Chemical Co., St. Louis, MO, USA). To eliminate genomic DNA contamination from the RNA, the RNA samples were treated with RNase-free DNase. Four micrograms of RNA was treated with $1 \mu \mathrm{L}$ of RQ1 RNasefree DNase in a $1 \mathrm{x}$ reaction mixture of RQ1 DNase buffer 
plus $1 \mu \mathrm{L}$ of $\mathrm{RNasin}^{\circledR}$ (RNase Inhibitor from GE Healthcare $\mathrm{UK}, \mathrm{Ltd})$ for $30 \mathrm{~min}$ at $37^{\circ} \mathrm{C}$. The reaction was stopped by adding RQ1 DNase stop solution and incubating the mixture at $65^{\circ} \mathrm{C}$ for $10 \mathrm{~min}$. Following DNase (GE Healthcare UK, Ltd) treatment, $2 \mu \mathrm{g}$ of total RNA was subjected to reverse transcription using random hexamers (Roche Molecular Biochemicals, Germany) and MMLV-RT (GE Healthcare UK, Ltd) in a $20 \mu 1$ reaction mixture. PCR amplification was carried out using a $2 \mu \mathrm{l}$ aliquot of cDNA and specific primers in a $25 \mu \mathrm{l}$ reaction volume. For amplification, the following reaction parameters were used: dNTPs each: 200 $\mu \mathrm{M}$; PCR reaction buffer 1x; sense-primer (forward) $50 \mathrm{ng}$; antisense-primer (reverse) $50 \mathrm{ng}$; template DNA $\sim 100 \mathrm{ng}$ (except in negative control PCR) DNA polymerase 1-2 U, The final reaction volume was $25 \mu \mathrm{L}$. An additive like DMSO was used at a concentration of $5 \%$ to $10 \%$ for GCrich templates.

A control reaction without reverse transcriptase was included in every set of RT-PCR reactions to verify the absence of genomic DNA contamination. Preliminary studies were carried out to arrive at the optimum temperature, primer concentrations and template to establish the linear range of RNA amplification. An $18 \mu \mathrm{l}$ aliquot of the PCR product was electrophoresed on a $1.5 \%$ agarose (GE Healthcare UK, Ltd) gel containing Ethidium Bromide (Sigma Chemical Co., St. Louis, MO, USA). Cyclophilin was used as an internal control. The sequences of the primers used in the present study and the RT-PCR details are given in Table 1. Analysis of images was carried out using a Kodak Electrophoresis and Gel Documentation Analysis System (EDAS-120). The relative ratio of the intensity of the gene of interest was calculated with respect to the internal control, and statistical analysis was carried out.

The authenticity of all the RT-PCR products described in this study was confirmed by purification of transcripts from agarose gels using a gel purification kit (Qiagen, Germany) and sequencing using the ABI Prism 377 automated DNA sequencer.

\subsection{Microarray Analysis}

\subsubsection{RNA Labeling and Hybridization}

Total RNA isolated from euthyroid and hyperthyroid neonatal rat Sertoli cells was reverse transcribed into cDNA and labeled using a tyramide signal amplification kit (NEN, Perkin-Elmer) with fluorescein or biotin. Hybridization was carried out by mixing equal quantities of experimental cDNA, control or treated sample labeled with fluorescein or biotin, with the spots on the slides under appropriate conditions. Stringent washes (6XSSPE $+0.005 \%$ Sarcosine for $1 \mathrm{~min}$ at room temperature; $2^{\text {nd }}$ wash with $0.06 \mathrm{X}$ $\mathrm{SSPE}+0.005 \%$ Sarcosine for $1 \mathrm{~min}$ at room temperature, followed by treatment with stabilization and drying solution at room temperature for $30 \mathrm{sec}$.) were carried out to remove excess or unbound labeled sample.

\subsubsection{Scanning of Slides}

Differential gene expression was assessed by scanning the hybridized arrays with an Axon scanner, using the Genepix Pro program. Hybridized slides were scanned first in the Cy5 channel and then the Cy 3 channel, as Cy5 is more susceptible to photo-degradation than Cy3. Data from each

Table 1. List of Primers and Sequences

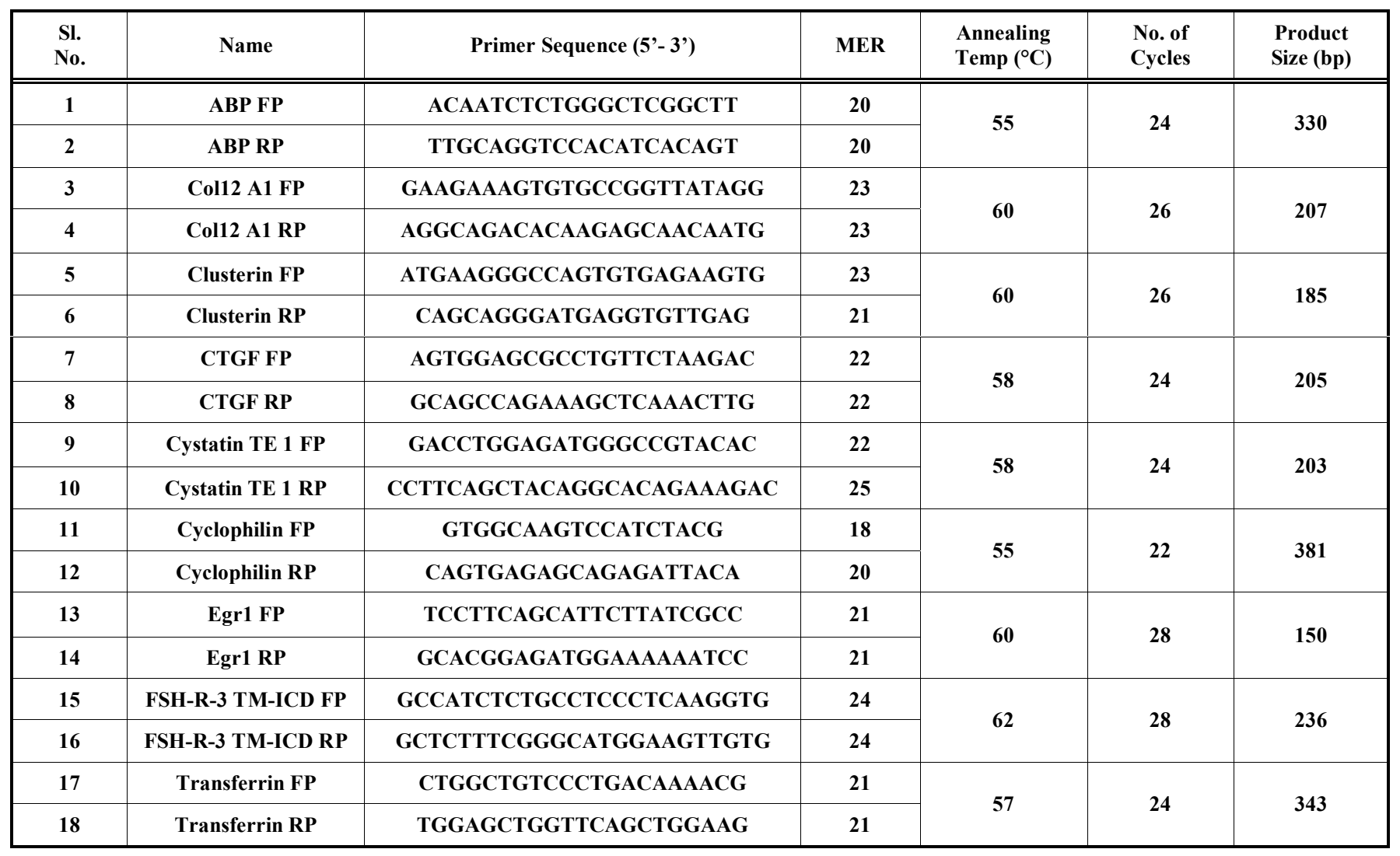


fluorescence channel were collected and stored as separate 16-bit TIFF images. These images were analyzed to calculate the relative expression levels of each gene and to identify differentially expressed genes. Each hybridized slide was scanned at different PMT gains. Scanning at different PMT gains, i.e., at very low PMT gain, does not allow the signal intensities of the Cy3 and Cy5 to be saturated. Scanning at medium PMT gains allows the signal intensities of both channels to be balanced, and, finally, scanning at higher PMT gains increases all the weak signal intensities of both channels.

\subsubsection{Image Processing and Quality Control}

Image processing and data extraction were done using the Genepix Pro program, and quality control of the slides was done using such parameters as background distribution, dye bias or dye specks.

\subsubsection{Image Processing}

\subsubsection{Gridding}

Depending upon the number of grids and number of rows and columns in each grid of the array, gridding was performed.

\subsubsection{Aligning of Features}

The Genepix Pro program automatically aligns both the blocks and spots on the image of the array. Some of the spots which could not be aligned automatically were manually aligned.

\subsubsection{Flagging}

The Genepix Pro program automatically flags the spots that are bad or absent. Manually flagging for some of the spots was also done for good and bad by circling them, or by putting a cross through them.

\subsubsection{Raw Data}

After gridding on the image, data were extracted for all the features in the image and saved as GPR files (Genepix Results file).

\subsubsection{Normalization of Raw Data}

Raw data were normalized using multiple methods. The best normalization method is one which yields a ratio median close to 1 and duplicate spots variance less. Gridwise normalization was chosen as the optimum for the slides. Normalization was calculated for each grid, as follows: Calculation of Normalization factor $=\mathrm{Sum}$ of $\mathrm{CH} 1$ Intensity/CH2-Intensity (excluding control and non-array specific spots); Calculation of Raw Ratio $=\mathrm{CH} 1$ Intensity/CH2-Intensity; Calculation of Normalized Ratio=Raw Ratio (for each spot)/Normalization factor (for the grid). Likewise, Ratio was calculated for spots in each grid separately.

\subsubsection{Ranking of Differentially Regulated Genes}

Differential regulation of genes was ascertained on the basis of genes that were at least one-fold up- or downregulated in more than $50 \%$ of the slides/experiments. Thus, up- and down-regulated genes were ranked on the basis of average fold change, consistency of the fold change across experiments, and intensity of the spots and flags.

\subsubsection{Data Analysis}

The data obtained after normalization were analyzed using a hierarchical clustering program called "Cluster" that uses standard statistical algorithms to arrange genes according to similarity in pattern of gene expression. The average linkage clustering technique was used to cluster the data. For cluster analysis, a table was constructed in which rows represent all genes for which data have been collected, columns represent individual array experiments, and each cell represents the measured $\mathrm{Cy} 5 / \mathrm{Cy} 3$ fluorescence ratio at the corresponding target element on the appropriate array. All ratio values were log transformed (base 2 for simplicity) to treat inductions or repressions of identical magnitude as numerically equal, but with opposite sign. Clusters were made for genes belonging to a common pathway or genes with a similar or common function. The data obtained from Cluster were displayed graphically using a program called "Tree view".

The data were normalized by calculating the ratio between the intensities of the two channels. Genes that were at least two-fold up/down-regulated in more than $50 \%$ of the experiment were selected for further analysis. Thus, up/down-regulated genes were ranked on the basis of average fold change, consistency of the fold change across experiments, and the intensity of the spots. For the present study, genes were delimited on the basis of their known biological functions.

\section{6. Statistical Analysis}

Data are presented as mean \pm S.E.M. of at least three independent experiments performed with the same treatment protocol, and data were analyzed using the unpaired twotailed ' $t$ ' test.

\section{RESULTS}

\subsection{Thyroid Hormone Regulates Sertoli Cell Proliferation}

\subsubsection{In Vitro Regulation of Sertoli Cell Proliferation}

To understand the role of thyroid hormone on Sertoli cell proliferation, Sertoli cells were isolated from 10-day-old neonatal rats. In our studies, we found that the peak of proliferation was seen on day 9 after birth [30], and an equal number of Sertoli cells $(40,000)$ were cultured under three different conditions. One group of Sertoli cells was cultured in the presence of $250 \mathrm{ng} / \mathrm{mL}$ of oFSH. Another group was cultured in the presence of $250 \mathrm{ng} / \mathrm{mL}$ oFSH and $100 \mathrm{nM} \mathrm{T3}$, and the last group, which served as a control, received vehicle (medium only). After $16 \mathrm{~h}$ of incubation, all three groups of Sertoli cells were pulsed with $10 \mu \mathrm{M}$ BrdU for four hours. Results revealed increased proliferation of Sertoli cells in the presence of oFSH (Fig. 1A). In contrast, in the group of Sertoli cells which were treated with both oFSH and T3, a decrease in Sertoli cell proliferation was observed, suggesting that T3 inhibited the FSH-stimulated proliferation of neonatal rat Sertoli cells in vitro. MTT assay revealed that the cells were viable at the end of the experiment in all three treatment groups (Fig. 1B), thus ruling out the possibility that the decrease in proliferation resulted from the death of Sertoli cells in the presence of T3. 
A

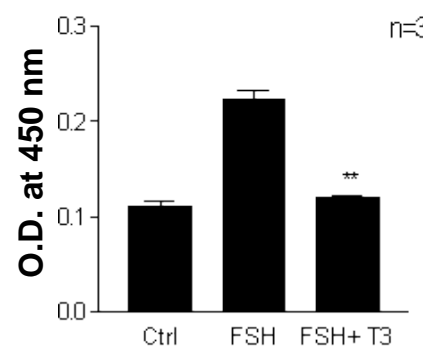

C

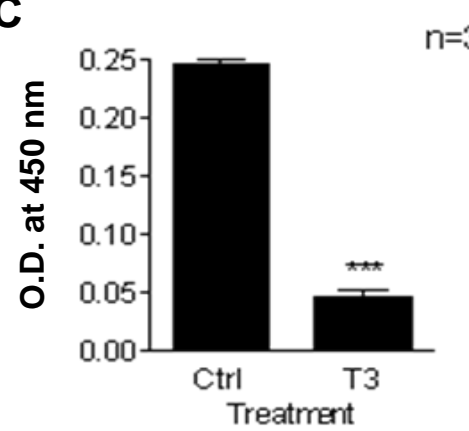

B

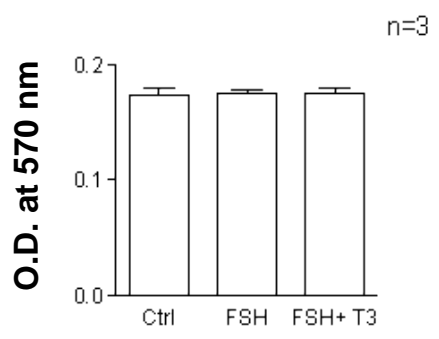

D

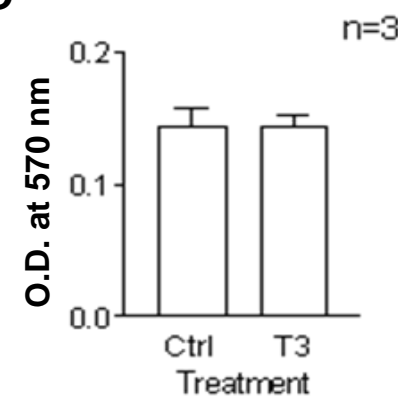

Fig. (1). Regulation of Sertoli cell proliferation by thyroid hormone.

A. BrdU incorporation analysis of neonatal rat Sertoli cells cultured in the presence of oFSH+T3 revealed a significant decrease $(\mathrm{P}<0.01)$ compared to proliferation stimulated by FSH. B. MTT assay for viability of the cells at the end of the experiment. C. BrdU incorporation analysis revealed a significant $(\mathrm{P}<0.001)$ decrease in the proliferation of neonatal rat Sertoli cells following administration of $\mathrm{T} 3$ to neonatal rats. D. MTT assay for viability of the cells used in Figure $\mathbf{1 C}$ at the end of the experiment. The values represent mean \pm SEM of three independent experiments.

\subsubsection{In Vivo Regulation of Sertoli Cell Proliferation}

To validate the observation that thyroid hormone inhibits the FSH-stimulated proliferation of the Sertoli cells, the effect of administration of thyroid hormone to neonatal rats from day one postnatal was evaluated. One group of neonatal rats was subcutaneously administered $\mathrm{T} 3$ in saline (100 $\mu \mathrm{g} / \mathrm{kg}$ body weight) each day from birth to 13 days postnatal. Another group received only saline (euthyroid). A decrease in proliferation of Sertoli cells in the hyperthyroid neonatal rat was seen compared to Sertoli cells in the euthyroid rat (Fig. 1C). Thus, as observed in both in vitro and in vivo experiments, it was established that thyroid hormone inhibits the proliferation of neonatal rat Sertoli cells. The results from the MTT assay established that the cells were viable at the end of the experiment in both treatment groups (Fig. 1D).

\subsection{Effect of Hyperthyroidism on Differentiation of Sertoli Cells}

\subsubsection{Expression of FSH-R}

Our previous studies revealed that the expression of FSH-R decreases with age in the differentiated Sertoli cells isolated from adult rats and that the expression of FSH-R is an important marker to distinguish between the undifferentiated and differentiated rat Sertoli cells [3]. Since arrest of proliferation is a prerequisite to initiate differentiation, we monitored the expression of FSH-R in euthyroid and hyperthyroid rat Sertoli cells. Using the RNA isolated from the euthyroid and hyperthyroid neonatal rat Sertoli cells, RT-PCR revealed that the expression of FSH-R was decreased significantly $(\mathrm{P}<0.01)$ in the Sertoli cells isolated from the hyperthyroid rats compared to the euthyroid rats (Fig. 2A \& B).

\subsubsection{Expression of Sertoli Cell Differentiation Markers}

In our previous study, we showed that the mRNA expression of both ABP and transferrin is higher in the adult rat Sertoli cells compared to neonatal rat Sertoli cells [3]. In view of this, we monitored the effect of hyperthyroidism on expression of $\mathrm{ABP}$ and transferrin in neonatal rat Sertoli cells. The expression of $\mathrm{ABP}$ and transferrin was upregulated in the hyperthyroid rat Sertoli cells (Fig. 2C and D). The results revealed that the expression of the known Sertoli cell differentiation markers is increased following administration of $\mathrm{T} 3$ to neonatal rats, suggesting that hyperthyroidism causes premature differentiation of the Sertoli cells.

\subsection{Microarray Analysis of Euthyroid and Hyperthyroid Rat Sertoli Cells}

Genes that were at least two-fold up- or down-regulated in more than $50 \%$ of the slides used for microarray analysis (three separate sets of slides) were considered to be differentially regulated. Overall, 70 genes were up-regulated, and 62 genes were down-regulated in the neonatal Sertoli cells following hyperthyroidism. Based on their known function, these genes were grouped into different functional classes, such as those related to proliferation, cytoskeleton, metabolism, steroidogenic pathway, proteases, and protease inhibitors. The average fold increase or decrease in the 
A
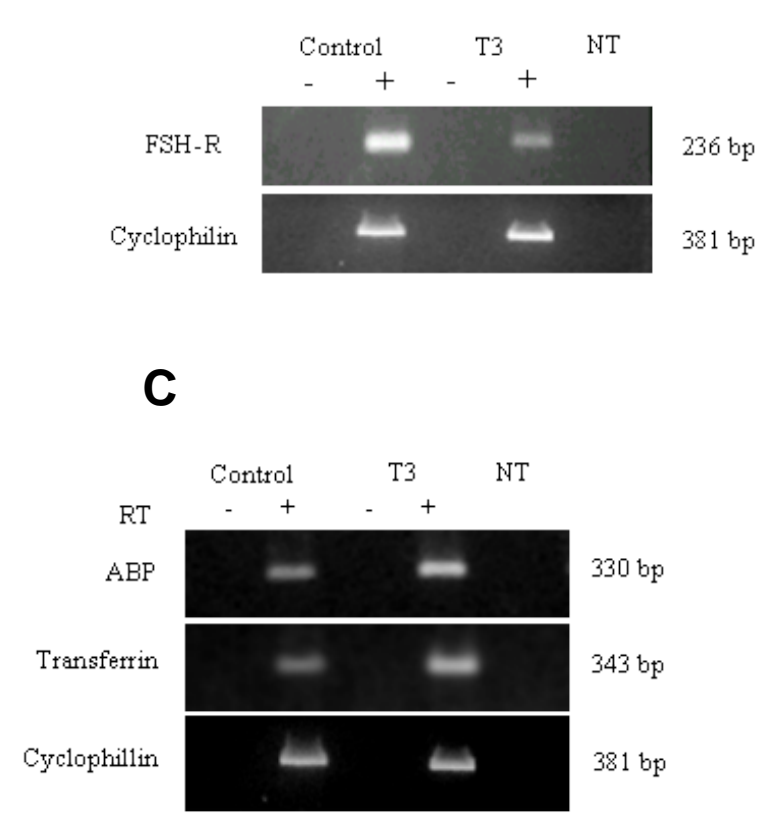

B

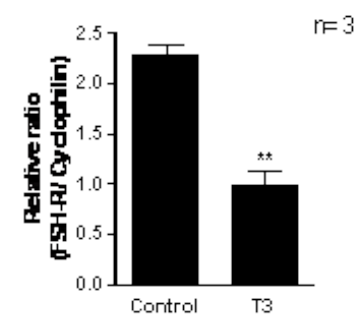

D

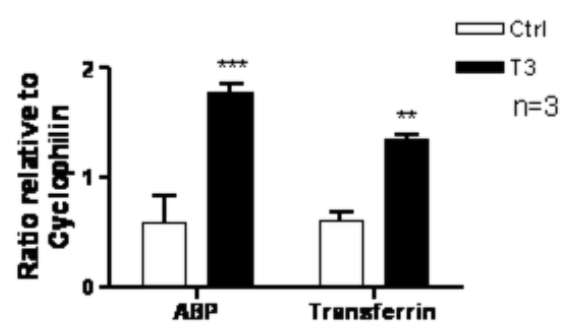

Fig. (2). Effect of T3 administration on Sertoli cell differentiation markers.

A. RT-PCR analysis for FSH receptor (FSH-R) from RNA isolated from the euthyroid and hyperthyroid neonatal rat Sertoli cells. B. Graphic representation of data provided in $2 \mathrm{~A}(\mathrm{P}<0.01)$. C. RT-PCR analysis for ABP and transferrin in the euthyroid and hyperthyroid neonatal rat Sertoli cells. D. Graphic representation of data provided in $2 \mathrm{C}$; the relative ratio is expressed with respect to the internal control cyclophilin. The figure is representative of three independent experiments. The values represent mean $\pm \mathrm{SEM}$.

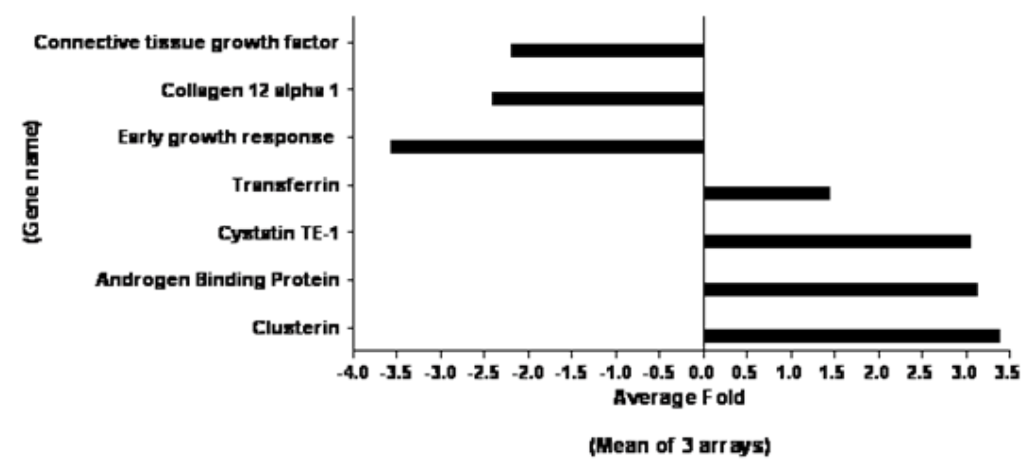

Fig. (3). Regulation of selected genes in neonatal Sertoli cells following induction of hyperthyroidism.

expression of selected genes is presented in Fig. (3). Microarray analysis results also revealed the up-regulation of known Sertoli cell differentiation markers, such as ABP, transferrin, protein kinase clusterin, and cystatin TE-1, following hyperthyroidism. However, cell growth promoters like early growth response protein (EGR), connective tissue growth factor (CTGF) and collagen XII alpha 1 (COL12A1) were down-regulated following neonatal hyperthyroidism (Fig. 3). To establish the role of thyroid hormone in Sertoli cell differentiation, the seven genes were selected on the basis of their known functions.

\subsubsection{Validation of the Microarray Results}

Semi-quantitative RT-PCR analysis was carried out to validate the expression of genes identified by microarray analysis, in addition to ABP and transferrin, which were up- regulated in hyperthyroid animals (Fig. 2C). RT-PCR analysis revealed a 3 -fold increase in clusterin expression in the 13-day-old hyperthyroid rat Sertoli cells (Fig. 4A and B), and the expression of cystatin TE-1 increased by almost 2.5fold in Sertoli cells following hyperthyroidism.

RT-PCR analysis for genes involved in cell growth, i.e., COL12A1, EGR and CTGF, revealed a significant $(\mathrm{P}<0.01)$ decrease in their expression following hyperthyroidism in neonatal rat Sertoli cells, and mRNA expression of EGR mRNA was almost undetectable. Similarly, the mRNA level of CTGF was also reduced to almost undetectable levels following treatment with thyroid hormone (Fig. 4A and B). Thus, the expression of the genes involved in cell growth was down-regulated following hyperthyroidism in neonatal rat Sertoli cells. The results of the microarray analysis also 
A

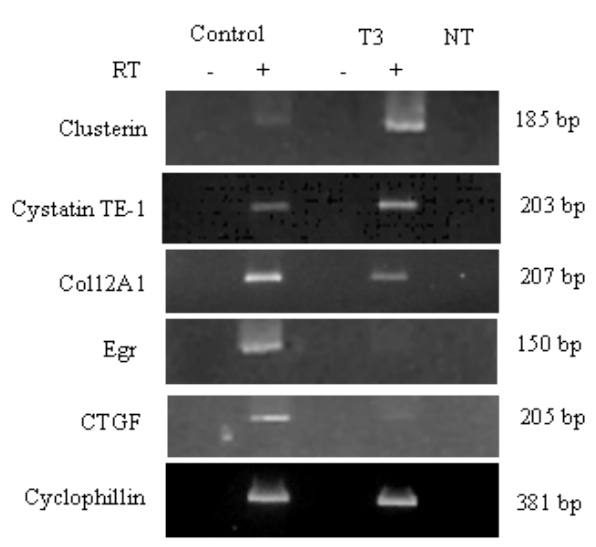

B

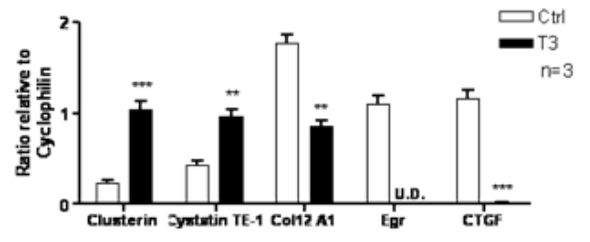

Fig. (4). Validation of the microarray results.

A. RT-PCR analysis for the expression of clusterin, cystatin TE-1, COL12A1, EGR and CTGF in the euthyroid and hyperthyroid neonatal rat Sertoli cells. B. The relative ratio is expressed with respect to the internal control cyclophilin. The figures are representative of three independent experiments. The values represent mean \pm SEM.

support the hypothesis that thyroid hormone inhibits Sertoli cell proliferation and induces differentiation.

\subsubsection{Effect of Deprivation of Endogenous FSH on the Expression of Selected Genes in Sertoli Cells}

It has been reported that FSH levels were reduced in T3-injected rats on days 5 and 7, but increased on day 23 after cessation of treatment. It should be noted that serum FSH and LH levels were elevated in both male and female pre-pubertal rats and remained low between day 21 and the immediate pre-pubertal period [31]. Studies by Rao et al. [32] have also suggested that thyroid hormone directly regulates FSH receptor gene expression in Sertoli cells. A part of this period corresponds to the period of hyperthyroidism induced in our study, and in spite of the increased FSH levels during hyperthyroidism [21], it should be noted that Sertoli cell proliferation was inhibited, suggesting that changes in the genes involved in inhibition of proliferation or induction of differentiation could be different under both FSH deprivation and hyperthyroidism. This is evident from the fact that RT-PCR analysis following FSH deprivation for clusterin and cystatin TE1 revealed no significant change in the expression level of these markers. These results suggest that arrest of proliferation by $\mathrm{FSH}$ deprivation did not result in an increase in differentiation markers. As expected, the level of CTGF expression, which indicates proliferation, was decreased following $\mathrm{FSH}$ deprivation, even though COL12A1 and EGR remained unaltered (Fig. 5A and B). As demonstrated earlier [30], following FSH deprivation, there was a decrease in the expression of PCNA Cyclin A2 and Cyclin E2 in the Sertoli cells, as assessed by RT-PCR, as well as a decrease in the incorporation of BrdU by more than $80 \%$. Both of these parameters are indicators of cell proliferation.

\subsubsection{Expression of Selected Genes in Differentiated Sertoli Cells of Adult Rat}

The results of microarray analysis suggested that thyroid hormone causes premature differentiation of the neonatal
Sertoli cells; therefore, we analyzed the expression profile of differentiation marker genes in the neonatal and adult rat Sertoli cells. RT-PCR analysis revealed that the mRNA expression of clusterin and cystatin TE-1 was at least twofold more in adult rat Sertoli cells, while the mRNA levels of COL12A1, EGR, and CTGF were significantly less in adult rat Sertoli cells (Fig. 6A and $\mathbf{B}$ ) compared to the neonatal rat. This shows that differentiation markers are more highly expressed in the adult rat Sertoli cells. Under these circumstances, we hypothesized that the prematurely differentiated Sertoli cells, following hyperthyroidism, should have the same expression profile as the adult differentiated Sertoli cells. Compare, for example, the T3 expression profile shown in Fig. (4) with the adult expression profile given in Fig. (6). It should also be noted that RT-PCR results revealed that the expression pattern of the genes selected from microarray analysis following euthyroidism was similar to neonatal Sertoli cells. In this case, compare the expression profile of control from Fig. (4) with the expression profile of the neonatal rat, as shown in Fig. (6). This suggests that the Sertoli cells from neonatal rats have prematurely differentiated following exposure to thyroid hormone and behave in a manner similar to normal adult Sertoli cells.

\section{DISCUSSION}

Although proliferation is generally arrested before differentiation occurs, it is possible that these two processes can occur simultaneously [33]. Previously, we have investigated molecular changes associated with differentiation of cells using BeWo choriocarcinoma cells and Leydig cells [34-36]. In the present study, we have extended this to Sertoli cells, and we analyzed the role of thyroid hormone and FSH in the differentiation of Sertoli cells. Sertoli cells are highly proliferative, but only during the early neonatal period, during which their number increases rapidly [17]. In vivo studies by Meachem et al. [17] revealed that FSH differentially effects Sertoli and germ cells in an age-dependent manner, promoting Sertoli cell 
A

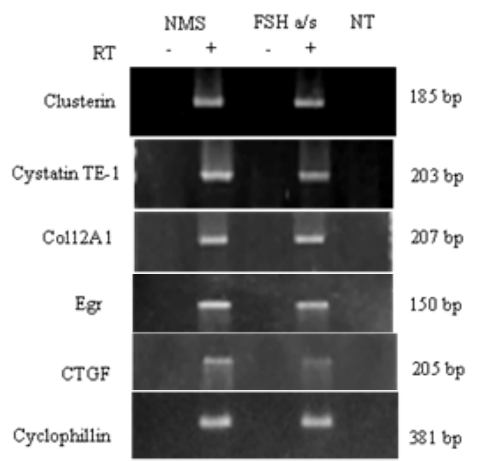

B

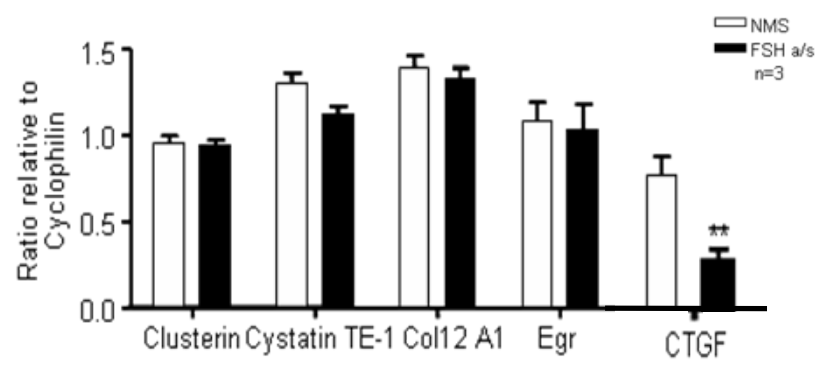

Fig. (5). RT-PCR analyses for selected genes following deprivation of endogenous FSH in neonatal rats.

A. RT-PCR analysis for clusterin, cystatin TE-1, COL12A1, EGR and CTGF in the neonatal rat Sertoli cells following neutralization of endogenous FSH. B. The relative ratio is expressed with respect to the internal control cyclophilin. The figures are representative of three independent experiments. The values represent mean \pm SEM.

mitosis on day 8 and supporting germ cell viability at day 18 . In contrast, our earlier studies revealed that the peak of proliferation with highly purified Sertoli cells is seen on day 9. By day 12, it decreases, and proliferation cannot be observed by day 18 postpartum [30]. Thus, the results obtained in the present study clearly established the dual role of FSH in Sertoli cell proliferation during immature stages and induction of differentiation during adult stages. Although it is possible that both processes may occur simultaneously, a clear demarcation of the time frame of initiation may not be possible. In addition, our earlier results [3] also established that the down-regulation of FSH receptor is indicative of loss of response to $\mathrm{FSH}$ by the immature rat Sertoli cells as far as proliferation is concerned. After the cessation of proliferation, Sertoli cells undergo differentiation, and their main function is secretion of growth factors, synthesis and maintenance of the blood-testisbarrier, and secretion of various proteins, such as proteases, protease inhibitors, and transport proteins, essentially to provide a microenvironment for the developing germ cells. Thus, the neonatal and adult rat Sertoli cells can be differentiated at the molecular level by the expression level of differentiation markers, with the adult being functionally more active. As such, these cells can be considered differentiated. Thyroid hormone is known to play an important role in the growth and development of Sertoli cells. Although Bortolussi et al. [37] report that the number of FSH receptors, as assessed by binding studies, increases after day 21 as they differentiate, these studies were carried out with crude homogenate and frozen sections. In contrast, we have employed highly purified cells and, as such, we were able to characterize Sertoli cells with the very sensitive RT-PCR approach to assess the expression of FSH receptor. Specifically, following hyperthyroidism, we observed that there is a decrease in the expression of FSH-R in the neonatal rat Sertoli cells, which normally have a high expression. This observation strengthens previous reports suggesting that thyroid hormone induces differentiation of neonatal Sertoli cells [9, 38].

By employing microarray analysis of RNA from euthyroid and hyperthyroid neonatal rat Sertoli cells, we observed an increase in the expression of transferrin cystatin TE-1, ABP, and clusterin. It should be noted that all these molecules are markers of Sertoli cell function. For example, it is known that ABP is necessary for the transport of androgen into the lumen to the epididymis, while transferrin is important for transport of iron to the developing germ cells, which otherwise do not have access to systemic iron by the presence of the blood-testis-barrier. Clusterin is a secretory glycoprotein present in most body fluids and is involved in a variety of physiological processes, including cell adhesion, cellular differentiation and apoptosis [39]. Cystatin TE-1 is a member of the cysteine protease inhibitor family. Cysteine peptidases have an important role in 
A

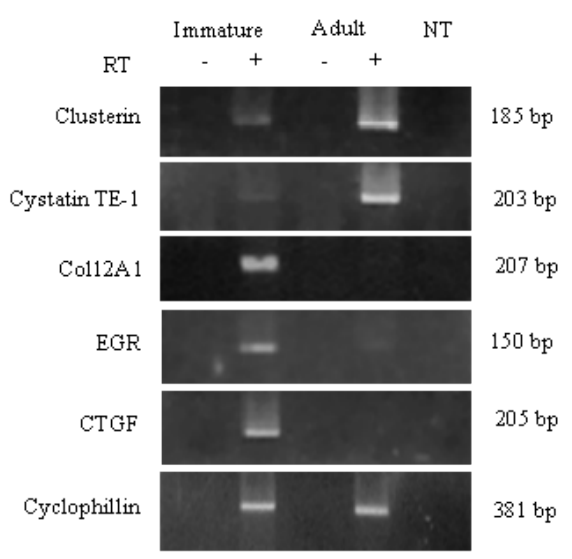

B

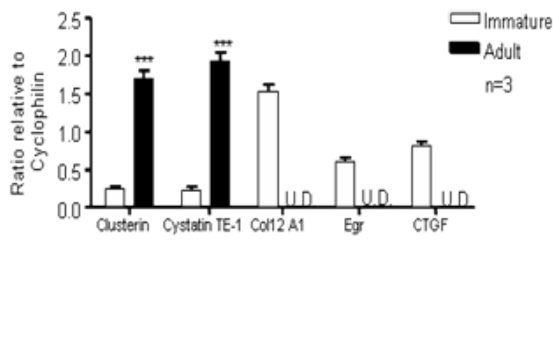

Fig. (6). Comparison of the expression of selected genes in neonatal and adult rat Sertoli cells.

A. RT-PCR analysis for clusterin, cystatin TE-1, COL12A1, EGR and CTGF in the neonatal and adult rat Sertoli cells. B. The relative ratio is expressed with respect to the internal control cyclophilin. The figures are representative of three independent experiments. The values represent mean \pm SEM.

physiological processes, such as intracellular protein degradation [40]. Thus, cystatin control over these proteases is important. Cystatins may also participate in the defense against microbial infections, which is another important function of Sertoli cells during adult stages [40]. It has been demonstrated that cystatin TE-1 is expressed only in Sertoli cells and epididymis, indicating that it plays a very specialized role in these tissues [41]. Hence, our study provides novel information regarding the role of thyroid hormone in the differentiation of Sertoli cells. In addition, our work supports previous observations [15] following hypothyroidism where the expression of several Sertoli cell factors, such as ABP, clusterin, and inhibin-beta B, were delayed at the mRNA level, including hemiferrin, a spermatid-specific mRNA. Furthermore, thyroid hormone replacement in PTU-treated animals decreased MIS and cerbA alpha mRNA expression to control levels [15]. It was also observed that the level of expression for clusterin and cystatin TE-1 increased in the adult Sertoli cells.

During our microarray studies, it was observed that the expression COL12A1 was down-regulated in Sertoli cells isolated from hyperthyroid rats. COL12A1 belongs to the collagen family of extracellular matrix (ECM) proteins which are involved in extra- cellular matrix remodeling, growth and proliferation of cells. The ECM proteins are also known to promote cellular proliferation through the regulation of immediate early genes, which are involved in proliferation. Earlier studies have also reported the modulation of basement membrane (BM) components, including type IV collagen, laminin and entactin expression, in prepubertal rat Sertoli cells by the thyroid hormone, as observed by immuno-cytochemical studies [39]. Western blot analysis of Sertoli cell-conditioned media indicated that thyroid hormone treatment of Sertoli cells significantly reduced type IV collagen secretion by $62 \%$, and even the RNA levels for type IV collagen alpha 1 chain were reduced by $50 \%$ after thyroid hormone treatment [42]. These observations demonstrated the ability of T3 to differentially regulate the expression of $\mathrm{BM}$ components and, hence, could be regarded as a part of the integrated mechanism by which thyroid hormone affects testicular development and differentiation [42].

In the present study, it was observed that the expression of EGR gene is down-regulated following treatment with thyroid hormone. The EGR gene is a transcription factor induced by stress or injury, mitogens, and differentiation factors $[43,44]$. Its expression is high in proliferating cells, and antisense to the EGR gene inhibits prostate tumor development in TRAMP mice [45]. The reduced expression of the EGR gene in adult rats supports its importance in the regulation of Sertoli cell proliferation. However, EGR gene expression was not significantly affected following the decrease in Sertoli cell proliferation by FSH deprivation, which points to an important distinction between arrest of proliferation by FSH deprivation and T3 treatment.

CTGF is an important matricellular regulatory factor involved in internal and external cell signaling, growth, and proliferation or differentiation of cells, depending on the cell type $[42,43]$. In vitro CTGF directly regulates the proliferation and differentiation of chondrocytes [46, 47]. The expression of this gene was observed to be downregulated by thyroid hormone treatment. In addition, the expression of COL12A1, EGR gene and CTGF was observed to be highly reduced or absent in the adult Sertoli cells. The arrest of proliferation is a prerequisite for initiation of differentiation [29]. However, while deprivation of FSH resulted in arrest of proliferation, we found that it did not result in the expression of markers characteristic of Sertoli cell differentiation. It should be noted that while the results of Ruwanpura et al. [48] suggest a direct action of FSH on germ cells, most of the studies $[12,49]$ reporting the role of FSH in spermatogenesis suggest that it acts indirectly by regulating the function of Sertoli cells. Our results also support such a conclusion and thus our results differ from those reported by Ruwanpura et al. [48]. However, induction of hyperthyroidism in neonatal rats results not only in the 
arrest of proliferation but also a decrease in the level of expression of differentiation markers in Sertoli cells. Thus, the results of the present study suggest that the molecular changes associated with FSH deprivation and hyperthyroidism appear to affect different pathways.

\section{ACKNOWLEDGEMENT}

AJR thanks the Department of Science and Technology for the Rajaramanna Fellowship award. The authors also thank the Indian Institute of Science, the Department of Science and Technology, the Department of Biotechnology, the Indian Council of Medical Research, the Indian government, as well as the Mellon Foundation USA, Conrad, USA, and the Rockefeller Foundation for the financial assistance provided during the course of this work. AJR wishes to thank Mrs. B.S. Shailaja for secretarial assistance.

\section{REFERENCES}

[1] Orth JM. Proliferation of Sertoli cells in fetal and postnatal rats: A quantitative autoradiographic study. Anat Rec 1982; 203: 485-92.

[2] Joyce KL, Porcelli J, Cooke PS. Neonatal goitrogen treatment increases adult testis size and sperm production in the mouse. $\mathrm{J}$ Androl 1993; 14: 448-55.

[3] Lekha CD, Rao AJ. Regulation of FSH receptor, PKI $\beta$, IL-6 and Calcium mobilization: Possible mediators of differential action of FSH. Mol Cell Endocrinol 2006; 247: 73-81.

[4] Means AR, Huckins C. Coupled events in the early biochemical actions of FSH on the Sertoli cells of the testis. Curr Top Mol Endocrinol 1974; 1: 145-65.

[5] Griswold MD, Mably ER, Fritz IB. FSH stimulation of DNA synthesis in Sertoli cells in culture. Mol Cell Endocrinol 1976; 4: $139-49$.

[6] Means AR, Dedman JR, Tash JS, Tindall DJ, van Sickle M, Welsh M.J. Regulation of the testis sertoli cell by follicle stimulating hormone. Annu Rev Physiol 1980; 42: 59-70.

[7] Orth JM. The role of follicle-stimulating hormone in controlling Sertoli cell proliferation in testes of fetal rats. Endocrinology 1984; 115: 1248-55.

[8] Boitani C, Stefanini M, Fragale A, Morena AR. Activin stimulates Sertoli cell proliferation in a defined period of rat testis development. Endocrinology 1995; 136: 5438-44.

[9] Buzzard JJ, Wreford NG, Morrison JR. Thyroid hormone, retinoic acid, and testosterone suppress proliferation and induce markers of differentiation in cultured rat Sertoli cells. Endocrinology 2003; 144: 3722-3731.

[10] Johnston H, Baker PJ, Abel M, et al. Regulation of Sertoli cell number and activity by follicle-stimulating hormone and androgen during postnatal development in the mouse. Endocrinology 2004; 145: 318-29.

[11] Kirby JD, Jetton AE, Cooke PS, et al. Developmental hormonal profiles accompanying the neonatal hypothyroidism-induced increase in adult testicular size and sperm production in the rat. Endocrinology 1992; 131: 559-65.

[12] Griswold MD. In: Russel LD, Griswold MD, Eds. Action of FSH on mammalian Sertoli cells. The Sertoli cell cache River Press: New Zealand 1993; 493-508.

[13] Tindall DJ, Vitale R, Means AR. Androgen binding protein as a biochemical marker of formation of the blood-testis barrier. Endocrinology 1975; 97: 636-48.

[14] Jannini EA, Olivieri M, Francavilla S, Gulino A, Ziparo E, D'Armiento M. Ontogenesis of the nuclear 3,5,3'-triiodothyronine receptor in the rat testis. Endocrinology 1990; 126: 2521-6.

[15] Bunick D, Kirby J, Hess RA, Cooke PS. Developmental expression of testis messenger ribonucleic acids in the rat following propylthiouracil-induced neonatal hypothyroidism. Biol Reprod 1994; 51: 706-13.

[16] Holsberger DR, Buchold GM, Leal MC et al. Cell cycle inhibitors p27Kip1 and p21Cip1 regulate murine Sertoli Cell proliferation. Biol Reprod 2005; 72: 1429-36.

[17] Meachem SJ, Ruwanpura SM, Ziolkowski J, Ague JM, Skinner MK, Loveland KL. Developmentally distinct in vivo effects of FSH on proliferation and apoptosis during testis maturation. J Endocrinol 2005; 186: 429-46.

[18] Cooke PS, Meisami E. Early hypothyroidism in rats causes increased adult testis and reproductive organ size but does not change testosterone levels. Endocrinology 1991; 129: 237-43.

[19] Cooke PS, Zhao YD, Bunick D. Triiodothyronine inhibits proliferation and stimulates differentiation of cultured neonatal Sertoli cells: possible mechanism for increased adult testis weight and sperm production induced by neonatal goitrogen treatment. Biol Reprod 1994; 51: 1000-5.

[20] Hess RA, Cooke PS, Bunick D, Kirby JD. Adult testicular enlargement induced by neonatal hypothyroidism is accompanied by increased Sertoli and germ cell numbers. Endocrinology 1993; 132: 2607-13.

[21] van Haaster LH, de Jong FH, Docter R, de Rooij DG. High neonatal triiodothyronine levels reduce the period of Sertoli cell proliferation and accelerate tubular lumen formation in the rat testis, and increase serum inhibin levels. Endocrinology 1993; 133: 755-60.

[22] van Haaster LH, De Jong FH, Docter R, De Rooij DG. The effect of hypothyroidism on Sertoli cell proliferation and differentiation and hormone levels during testicular development in the rat. Endocrinology 1992; 131: 1574-6.

[23] Orth JM, Gunsalus GL, Lamperti AA. Evidence from Sertoli celldepleted rats indicates that spermatid number in adults depends on numbers of Sertoli cells produced during perinatal development. Endocrinology 1988; 122: 787-4.

[24] De Franca LR, Hess RA, Cooke PS, Russell LD. Neonatal hypothyroidism causes delayed Sertoli cell maturation in rats treated with propylthiouracil: evidence that the Sertoli cell controls testis growth. Anat Rec1995; 242: 57-69.

[25] Simorangkir DR, de Kretser DM, Wreford NG. Increased numbers of Sertoli and germ cells in adult rat testes induced by synergistic action of transient neonatal hypothyroidism and neonatal hemicastration. J Reprod Fertil 1995; 104: 207-13.

[26] Auharek SA, de França LR. Postnatal testis development, Sertoli cell proliferation and number of different spermatogonial types in C57BL/6J mice made transiently hypo- and hyperthyroidic during the neonatal period. J Anat 2010; 216: 577-88.

[27] Sriraman V, Sairam MR, Rao AJ. Evaluation of relative roles of LH and FSH in regulation of differentiation of Leydig cells using an ethane 1,2-dimethylsulfonate-treated adult rat model. J Endocrinol 2003; 176: 151-61.

[28] Tung PS, Fritz BI. In: Celis JE, Ed. Isolation of Sertoli cells and Their Properties in Culture. Cell Biology A Laboratory Handbook. California, USA: Academic Press 1998; pp. 186-94.

[29] Mosmann T. Rapid colorimetric assay for cellular growth and survival: Application to proliferation and cytotoxicity assays. J Immunol Methods 1983; 65: 55-63.

[30] Lekha C. Differential role of FSH: A study using Sertoli cells and epididymal cells. Thesis; Bangalore Indian Institute of Science 2005.

[31] Döhler KD, Wuttke W. Serum LH. FSH, prolactin and progesterone from birth to puberty in female and male rats. Endocrinology 1974; 94: 1003-8.

[32] Rao JN, Liang JY, Chakraborti P, Feng P. Effect of thyroid hormone on the development and gene expression of hormone receptors in rat testes in vivo. J Endocrinol Invest 2003; 26: 435-43.

[33] Kranenburg O, van der Eb AJ, Zantema A. Cyclin-dependent kinases and $\mathrm{pRb}$ : regulators of the proliferation-differentiation switch. FEBS Lett 1995; 367:103-6.

[34] Neelima PS, Rao AJ. Gene expression profiling during Forskolin induced differentiation of BeWo cells by differential display RTPCR. Mol Cell Endocrinol 2008; 281: 37-46.

[35] Anbalagan M, Rao AJ. Collagen IV mediated signaling is involved in progenitor Leydig cells proliferation. Reprod Biomed Online 2004; 9: 391-403.

[36] Anbalagan M, Yashwanth R, Rao AJ. DD-RT-PCR identifies 7 dehydrocholesterol reductase as a key marker of early Leydig cell steroidogenesis. Mol Cell Endocrinol 2004; 219: 37-45.

[37] Bortolussi M, Zanchetta R, Belvedere P, Colombo L. Sertoli and Leydig cell numbers and gonadotropin receptors in rat testis from birth to puberty. Cell Tissue Res 1990; 260: 185-91.

[38] Holsberger DR, Jirawatnotai S, Kiyokawa H, Cooke PS. Thyroid hormone regulates the cell cycle inhibitor p27Kip1 in postnatal murine Sertoli cells. Endocrinology 2003; 144: 3732-8. 
[39] Behrens P, Jeske W, Wernert N, Wellmann A. Down regulation of clusterin expression in testicular germ cell tumors. Pathobiology 2001; 69: 19-23.

[40] Abrahamson M, Alvarez-Fernandez M, Nathanson CM. Cystatins. Biochem Soc Symp 2003; 70: 179-99.

[41] Li Y, Friel PJ, Robinson MO, McLean DJ, Griswold MD. Identification and characterization of testis- and epididymisspecific genes: cystatin SC and cystatin TE-1. Biol Reprod 2002; 67: 1872-80.

[42] Ulisse S, Rucci N, Piersanti D, et al. Regulation by thyroid hormone of the expression of basement membrane components in rat prepubertal Sertoli cells. Endocrinology 1998; 139: 741-7.

[43] Baron V, De Gregorio G, Krones-Herzig A, et al. Inhibition of Egr1 expression reverses transformation of prostate cancer cells in vitro and in vivo. Oncogene 2003; 22: 4194-204.

[44] Ohtani K, Egashira K, Usui M, et al. Inhibition of neointimal hyperplasia after balloon injury by cis-element 'decoy' of early growth response gene-1 in hypercholesterolemic rabbits. Gene Ther 2004; 11: 126-32.
[45] Nishida $\mathrm{T}$, Kubota S, Fukunaga $\mathrm{T}$, et al. CTGF/Hcs24, hypertrophic chondrocyte-specific gene product, interacts with perlecan in regulating the proliferation and differentiation of chondrocytes. J Cell Physiol 2003; 196: 265-75.

[46] Safadi FF, Xu J, Smock SL, et al. Expression of connective tissue growth factor in bone: its role in osteoblast proliferation and differentiation in vitro and bone formation in vivo. J Cell Physiol 2003; 196: 51-62.

[47] Fukunaga T, Yamashiro T, Oya S, Takeshita N, Takigawa M, Takano-Yamamoto T. Connective tissue growth factor mRNA expression pattern in cartilages is associated with their type I collagen expression. Bone 2003; 33: 911-18.

[48] Ruwanpura SM, McLachlan RI, Stanton PG, Meachem SJ. Follicle-stimulating hormone affects spermatogonial survival by regulating the intrinsic apoptotic pathway in adult rats. Biol Reprod 2008; 78: 705-13.

[49] Walker WH, Cheng J. FSH and testosterone signaling in Sertoli cells. J Soc Reprod Fertil 2005;130: 15-28.

Received: March 04, 2011

Revised: May 05, 2011

Accepted: May 06, 2011

(C) Dahia et al.; Licensee Bentham Open.

This is an open access article licensed under the terms of the Creative Commons Attribution Non-Commercial License (http://creativecommons.org/licenses/by-nc/3.0/) which permits unrestricted, non-commercial use, distribution and reproduction in any medium, provided the work is properly cited. 